\title{
A potência de imaginar: arte, cultura e trabalho na economia dos bens abundantes
}

\author{
Sharine Machado Cabral Melo
}

Resumo: Este artigo tem como ponto de partida alguns dos enunciados que atualmente incidem sobre o fazer artístico, especialmente as propostas sobre a economia criativa, a economia das artes ou a economia da cultura. Em geral, eles se baseiam na possibilidade de extrair riquezas do pensamento, das redes e dos afetos. O apelo crescente por criatividade, que decorre desses discursos, leva a críticas sobre a exploração do trabalho criativo e sua inserção nos processos capitalistas. Todo esse movimento pode ser lido pelo viés da biopolítica, uma forma de poder que se estende por todos os domínios da vida. Mas é também essa dinâmica que faz da criação artística um campo de resistência e de disputa política em que concorrem vozes provenientes de diversos locais da sociedade.

Palavras-chave: economia criativa; artes; biopolítica.

Abstract: The power to imagine: art, culture and work in the economy of abundant goods - This paper has as its starting point some of the utterances that focuses on artistic activities, especially those proposals about creative economy, arts economy or culture economy. They are, in general, based on the possibility of extracting richness of thought, of networks and of affect. The growing request for creativity, which elapses from these discourses, leads to criticisms about creative labour's exploitation and its insertion into capitalistic processes. All these movements can be read from biopolitics point of view, a sort of power extended throughout all the domains of life. This dynamic is also what turns artistic creation into a field of resistance and of political struggle in which different voices compete from different areas of the society.

Keywords: creative economy; arts; biopolitics.

\section{O que se diz sobre a criatividade, a cultura e as artes}

Em comentário à obra de Foucault, Deleuze (2005, p. 58-64) afirma que uma época é composta por visibilidades e por enunciados. Em um plano, há "formas de luminosidade", o que se vê; no outro, há aquilo que se diz. Não há o primado de um plano sobre 
o outro: eles são paralelos e irredutíveis. Mas isso não quer dizer que os discursos sejam apartados do mundo tangível. Afinal, até mesmo o sujeito é um "conjunto de variáveis do enunciado": "o que é primeiro é um diz-se, murmúrio anônimo no qual posições são apontadas para sujeitos possíveis". Embora não negasse a liberdade humana, como pode parecer (sempre é possível reagir), Foucault (apud VEYNE, 2011) acreditava que são os processos de subjetivação que constituem os sujeitos, que são "modelados", em cada época, pelos discursos e pelos dispositivos em voga.

Para o filósofo (ibidem), os discursos são o diferencial de uma época, aquilo que a torna singular. Eles se espalham pelas mídias de massa ou digitais e também pelas conversas entre as pessoas, por falas de autoridades, por relatórios de governo. São técnicas de comunicação distintas que reforçam enunciados semelhantes, como um ritornelo. Por isso, funcionam também como dispositivos de poder, capazes de afetar as condutas individuais. Essas técnicas de comunicação criam camadas de sentido que incidem sobre os acontecimentos, transformando o modo como são compreendidos.

No campo das artes e da cultura não é diferente. Ao olharmos para o fazer artístico atual, iluminam-se linguagens diversas: artes visuais, arte digital, cinema e vídeo, circo, dança, literatura, música, performance, teatro, e todas as suas transversalidades. As propostas críticas em relação ao consumismo exacerbado, à economia e à política dividem o espaço com obras de caráter mais comercial, com retomadas das culturas populares e tradicionais (as rodas de samba, a capoeira, o artesanato) e com as poéticas que se articulam nas periferias (como o hip-hop); a música de câmara e a música experimental são ouvidas ao lado dos sons eletrônicos, do jazz, do rock e de tantas outras vertentes.

É claro que, em meio à aparente vitalidade, sempre há padrões e clichês que se repetem ou uma lógica mercantil que muitas vezes implica todos os envolvidos nos processos: artistas, produtores, gestores culturais, curadores, entre outros (GREINER, 2012). Contudo, há também uma potência que busca abrir novos espaços nesse ambiente por vezes já tão saturado pelos processos capitalistas: as iniciativas de crowdfunding, os artistas que se aprofundam em sua pesquisa e as possibilidades dos códigos abertos da internet são alguns exemplos.

Mas o que se diz sobre todo esse movimento? Quais enunciados se desprendem das diversas formas de comunicação? Em relatórios de governos e de organizações públicas ou privadas, discursos políticos, teses de administração, nós nos deparamos com termos como "economia criativa", "economia da cultura" ou "economia das artes". Algumas peças de comunicação veiculadas pelo Ministério da Cultura (MinC) em sua página no Facebook são ilustrativas. As chamadas para participação nos colegiados regionais são recorrentes e, nos documentos que resultam dessas reuniões, também divulgados na internet, são feitas menções ao caráter econômico da cultura e à diversidade. No dia 15 de junho de 2016, por exemplo, o MinC publicou, nas redes sociais, a seguinte notícia, que tem como fonte um relatório da FIRJAN (Federação das Indústrias do Rio de Janeiro): 
A indústria cultural impacta positivamente o PIB brasileiro. O setor gera emprego, renda e tem papel de destaque no desenvolvimento da cadeia produtiva (...) Pesquisas apontam que a participação do setor no PIB varia de $1,2 \%$ a $2,6 \%$. (BRASIL, 2016)

Outro exemplo vem do SEBRAE (Serviço Brasileiro de Apoio às Micro e Pequenas Empresas), em um texto sobre a atuação na área de economia criativa, que foi publicado em seu site:

É preciso transformar a habilidade criativa natural em ativo econômico e recurso para o desenvolvimento de negócios duradouros. Torna-se imperioso, portanto, estimular modelos inovadores para o desenvolvimento da economia criativa brasileira (SEBRAE, 2016).

Essa tendência teve seu auge na década de 1990, impulsionada pelos modos de produção pós-industrial e pelas teorias sobre o "capitalismo cognitivo" (MOULIERBOUTANG, 2011) ou sobre o "capitalismo imaterial", como preferem Toni Negri e Maurizio Lazzarato (2001). Também ganhavam visibilidade as obras de David Throsby (2008), sobre as indústrias culturais, e de Richard Florida (2012), sobre a "economia criativa". Todas essas teorias se refletiam nos discursos políticos. Em 1994, o Primeiro Ministro da Austrália nomeou seu país de "nação criativa" e, em 1997, Tony Blair formou uma equipe para mapear as indústrias criativas no Reino Unido. Críticas acadêmicas e períodos de crise financeira acabaram por diluir seu vigor inicial, porém, vinte anos após as primeiras iniciativas, a noção de uma "economia criativa" ainda ressoa.

No Brasil', a Secretaria de Economia Criativa foi criada somente em 2012 e fechada em 2015, mas a ideia central persiste em diversos documentos. O Plano Nacional de Cultura (PNC), instituído pela Lei 12.343, de 2 de dezembro de 2010, tem a finalidade de implementar, até 2020, políticas públicas de longo prazo, "voltadas à proteção e promoção da diversidade cultural brasileira". Um dos seus objetivos é justamente a inserção da cultura em modelos econômicos sustentáveis (BRASIL, 2011). Já a Política Nacional das Artes (PNA), que vem sendo construída em uma plataforma de participação social na internet, propõe o desenvolvimento de planos setoriais que também envolvem a "participação da cultura no desenvolvimento sociocultural" e a "consolidação da economia da cultura". (BRASIL, s.d.)

O que atravessa esses e outros enunciados semelhantes é a hipótese de que o pensamento, a imaginação e a capacidade de criar, em sua multiplicidade, são fontes praticamente inesgotáveis de riquezas. Tudo isso engendra uma economia de bens abundantes, aqueles que não se esgotam ao serem consumidos: uma peça de teatro é apresentada a diversos espectadores, um quadro é visto por todos os visitantes de

1 Embora os termos "economia criativa" e "economia da cultura" tenham sido, declaradamente, importados da bibliografia britânica, há diferenças significativas na proposta brasileira. A principal é a tendência a ressaltar a diversidade e não somente a produção em série de bens culturais. 
um museu e uma música pode ser executada por vários intérpretes, gravada em discos ou disponibilizada na internet, entre outros exemplos. É também por esse motivo que existe uma aproximação teórica com a economia do imaterial, aquela que, segundo Negri e Lazzarato (2001), é fundada justamente sobre a comunicação, o afeto e a cognição. Mas nem toda leitura desse cenário é positiva e, no debate, que atrai pesquisadores vindos de diferentes correntes teóricas, há um ponto em comum: as consequências, nem sempre desejáveis, da demanda crescente por criatividade que acomete a sociedade ocidental.

\section{A expansão da criatividade}

O pesquisador inglês David Hesmondhalgh (2013) afirma que a cultura migrou para o centro da economia em diversos países e, embora a estrutura das grandes companhias permaneça, há cada vez mais empresas pequenas e médias no setor. A internet e os telefones celulares multiplicaram o acesso aos conteúdos, e os bens culturais circulam para além das fronteiras nacionais. Desde o século XX, especialmente após a década de 1950, a atividade artística foi profissionalizada, o que contribuiu para que textos, sons e imagens se transformassem, em grande parte, em commodities, bens produzidos em série. Essa situação alimenta os debates sobre a autonomia dos artistas e as relações políticas e financeiras que se estabelecem nesses circuitos.

Kate Oakley (2009) também investiga algumas transformações históricas que começaram a tomar forma nos anos 1990 e aponta para a valorização recente das indústrias criativas. E, quando o termo "criatividade" substitui "arte" ou "cultura", há uma mudança em todo o modo de pensar. Para a autora, já não se trata do aprofundamento de linguagens e estéticas, nem da preservação das obras ou do patrimônio. É como se a arte, assim como qualquer outro bem criativo, já não pudesse ser valorizada em "seus próprios termos", mas que seu "valor" fosse medido principalmente pela capacidade de movimentar a economia ou de solucionar problemas sociais. A questão se acentua quando os discursos passam a ressaltar a "inovação" e não somente a "criatividade", o que remete a uma lógica propriamente empresarial.

Ora, quando a criação passa a ser requisitada dessa maneira, muitos pesquisadores se perguntam qual é, de fato, o papel das artes, já que elas se integram aos processos capitalistas, figurando, muitas vezes, ao lado de atividades claramente comerciais, como o design e a publicidade. Um dos filósofos que contribui para o debate é Giorgio Agamben (2012). Em seu primeiro livro, publicado ainda na década de 1970, o autor remonta à Grécia Antiga, propondo um exercício de genealogia. Naquela época, havia uma distinção entre a poesia (não no sentido da linguagem artística, mas no da palavra poíesis, que quer dizer produzir) e a práxis (fazer, agir). A poíesis, nas palavras de Agamben (ibidem, p. 120), era entendida como "a essência da obra", "o fato de que, nela, algo viesse ao ser a partir do não ser, abrindo, assim, o espaço da verdade", onde o homem pudesse encontrar "sua própria certeza" e assegurar "a liberdade e a duração de sua ação". 
A práxis, por sua vez, era vista como "o princípio do movimento", como a "vontade" que "caracteriza a vida", esta sim relacionada ao trabalho, que era fundamental para o sustento, embora fosse relegado aos escravos por remeter diretamente aos processos biológicos. Mas, ao longo da história ocidental, a distinção foi se diluindo, e o trabalho, "que ocupava o posto mais baixo na hierarquia da vida ativa", ascendeu à "posição central e de comum denominador de toda atividade humana" (ibidem, p. 118, 120). A partir dessa análise, Agamben (ibidem, p. 111,112) afirma que a arte também entrou na dimensão da práxis, já que, desde a emergência da estética, o acento foi deslocado ao "gênio criativo e às particularidades características do processo artístico em que ele encontra expressão".

Nós vemos que museus e galerias conservam e acumulam obras de arte para que sejam a todo momento disponíveis para a fruição estética do espectador, mais ou menos como acontece com as matérias-primas ou as mercadorias acumuladas em uma loja. Onde quer que uma obra de arte, hoje, seja produzida e exposta, o seu aspecto energético, isto é, o ser-em-obra, é apagado para dar lugar ao caráter de estimulante do sentimento estético, de mero suporte da fruição estética. (ibidem, p. 120, 121)

Além disso, há mecanismos, como a "economia de mercado", os modos "de produção e de circulação de obras" e a "empregabilidade", que fazem parte do circuito artístico. Nesse ambiente, torna-se necessário apresentar resultados, cumprir prazos e, também, buscar algum retorno financeiro, como não poderia deixar de ser. O problema ocorre quando a arte faz da satisfação de parâmetros externos seu principal propósito e, com isso, perde seu traço mais importante, segundo Christine Greiner (2014): a "aptidão desestabilizadora".

É também por isso que Pascal Gielen (2015) considera que a demanda excessiva por criatividade, não somente na arte, mas em outras atividades profissionais, pode fazer com que o sentido dessa palavra se esvazie. Para o autor, vivemos em um "mundo plano e úmido", uma vez que estamos constantemente em rede e mantemos relações fluidas com as pessoas e com as instituições, saltando de um projeto a outro sem o aprofundamento, a reflexão e o tempo que seriam necessários à criação.

Mas essas leituras por vezes causam uma sensação de impasse. Gielen (ibidem) se pergunta: quando tudo se torna criativo, ainda há lugar para a "verdadeira" criatividade? A noção de uma economia imaterial, que acompanha toda a discussão sobre a "economia criativa" ou a "economia da cultura", também gera dúvidas. Por um lado, ela pode levar ao entendimento de uma divisão cartesiana entre "corpo" e "mente", que vem sendo revista. Por outro, o entusiasmo pela "autonomia" dos trabalhadores parece negligenciar aspectos como insegurança e baixos salários, que atingem o setor cultural.

No entanto, apesar do uso muitas vezes equivocado do termo, quando Negri e Lazzarato (2001) escreveram um dos primeiros textos sobre o "trabalho imaterial", o que eles supunham não era a primazia da mente sobre o corpo, tampouco o mascaramento 
da exploração do trabalho. Pelo contrário, era a apropriação, por parte dos capitalistas, do "trabalho vivo", que depende menos do tempo empregado nas fábricas ou nos escritórios do que de uma "produtividade geral". Como vivemos mergulhados em um fluxo contínuo de pensamento, o trabalho não se esgota nas horas que passamos no interior de uma empresa, mas se estende por todo o circuito de consumo e de comunicação. Quando assistimos a um programa de televisão ou navegamos pela internet, estamos também produzindo, uma vez que estamos colaborando para o funcionamento do sistema capitalista.

Por isso, Negri e Lazzarato (ibidem) ressaltam a importância do "tempo livre" para o "desenvolvimento das individualidades" a partir do investimento em "si mesmo", em saberes diversos, artísticos e científicos. Essa dimensão já estava presente nos textos de Foucault do final dos anos 1970, em suas leituras sobre o capital humano e a biopolítica. E se, a partir da obra desse pensador, procurássemos, não somente investigar os problemas da busca incessante pela criatividade, mas entender o que, em nossa época, fez com ela fosse possível. O que há de singular em relação às artes, à cultura e também ao que se entende por trabalho ou por atividade produtiva? Quais os espaços que se abrem para a resistência dos artistas?

\section{Vida, trabalho e linguagem}

O método de pesquisa desenvolvido por Foucault (apud VEYNE, 2011, p. 49, 50, 54) consiste em encontrar rupturas, singularidades de cada época, em vez de buscar uma continuidade histórica. Para ele, estamos sempre imersos em discursos, que são as "lentes" através das quais os homens "percebem todas as coisas, pensam e agem". Os discursos funcionam como regimes de verdades que se impõem a todos, dominantes e dominados, sendo também imanentes aos dispositivos, ou seja, às "leis, aos atos, às falas ou às práticas que constituem uma formação histórica".

Em As Palavras e as Coisas, Foucault (2007) mostrou como, no século XVIII, a representação, sobre a qual se desenrolava o mundo clássico, deu lugar às categorias da vida, do trabalho e da linguagem - e foi principalmente através dessas lentes que se passou a ver o mundo desde então. O trabalho fragmentado das linhas de produção já havia se tornado uma unidade de medida, como na obra de Adam Smith. Era sobre o esforço necessário para produzir um produto que seu preço era calculado. Mas foi somente no século XIX, a partir das análises de David Ricardo, que o trabalho pôde se desenvolver segundo uma causalidade própria. Isso porque ele passou a ser entendido principalmente como algo de que se extrai um valor que, por sua vez, pode ser investido na fabricação de um novo bem de consumo e, assim, sucessivamente. Abria-se, dessa forma, a possibilidade da perspectiva histórica, que trazia consigo certo pensamento de finitude: afinal, em que atividade as pessoas estão investindo sua vida?

Na obra "O nascimento da biopolítica", Foucault (2008) avançou em sua investigação de outro ponto de vista. Segundo ele, os economistas liberais, como Smith e Ricardo, 
nunca se preocuparam de fato com a natureza do trabalho, uma vez que o reduziram ao fator tempo. A pergunta era: quantos trabalhadores são necessários, por qual período, para produzir determinado bem? Essa situação mudou em meados do século XX, quando surgiram as primeiras propostas neoliberais. O trabalho foi, então, reintroduzido nas análises econômicas, não mais do ponto de vista do empregador, mas agora do empregado: como ele investe em si mesmo, por meio da educação, e, em seguida, como utiliza os recursos de que dispõe? As pessoas passam a ser vistas como detentoras de "conhecimentos e competências" e o trabalho passa a ser, ao mesmo tempo, um elemento do processo produtivo e um "capital", o "capital humano".

Além disso, as análises econômicas não são mais, como no liberalismo, baseadas no livre comércio, mas pautadas principalmente pela concorrência entre as empresas. Nesse sentido, quando uma pessoa investe em si mesma e decide em quais atividades aplicar seus conhecimentos, ela se torna também uma unidade-empresa, uma empreendedora. Isso não significa, necessariamente, que todas as relações humanas sejam completamente dominadas pelo pensamento econômico, mas ele permeia as mais diversas esferas da vida, do emprego ao casamento, do lazer à educação dos filhos.

Para Rogério da Costa (2008), com essa análise, Foucault teve uma das primeiras percepções sobre o "capitalismo cognitivo" ou sobre a "economia do imaterial", que muitas vezes aparecem como um pano de fundo para os enunciados sobre a "economia criativa" ou a "economia da cultura". Além da força física e dos recursos naturais (finitos), que não cessam de ser explorados, busca-se extrair riquezas da própria subjetividade, do pensamento, da imaginação, do afeto e das redes. Em última instância, é a vida em si mesma que se torna uma fonte de recursos.

É também por isso que os estudos sobre o capital humano se aproximam das pesquisas sobre a biopolítica, iniciadas pelo próprio Foucault e expandida por outros autores. Segundo Peter Pelbart (2007), há uma forma de poder que "rege e regulamenta a vida". Mas esse poder não é apenas algo externo, como um soberano que reina sobre um território e decide quando seus súditos devem viver ou morrer. Para se obter um "domínio efetivo" sobre a população, é preciso que o poder seja também interno, que cada indivíduo o abrace "por sua própria conta e vontade". A vida se torna um objeto de poder não somente quando se penetra em todas as suas dimensões, "cognitiva, psíquica, física, biológica e até genética", mas quando cada um se propõe a reativá-la. De que maneira isso acontece?

Para Foucault (2013), a biopolítica produz sujeitos "ativos", porque convoca justamente o "trabalho sobre si". Não é coincidência que as primeiras preocupações com o governo da vida tenham surgido na mesma época em que nascia o liberalismo econômico e que tenham se aprofundado com o pensamento neoliberal. O que se espera é uma vida "capaz de condutas" (PELBART, 2013). É disso que se trata quando se exige cada vez mais criatividade e autonomia dos trabalhadores, quando se entende que eles devam buscar qualificação profissional, que devam se manter atualizados, que saibam formar redes. 
Ocorre que, se a vida é capaz de condutas, ela também é capaz de "insubmissões". É por isso que Pelbart (idem, 2007) aponta para "uma biopotência inaudita capaz de ameaçar as estruturas de comando e de dominação de uma sociedade de controle". Diversos autores, entre eles, Negri, Hardt e Lazzarato vêm pensando o contexto do capitalismo atual por esse viés, principalmente a partir da obra de Spinoza (2009). Para o filósofo, todo ser é um grau de potência, que se esforça em permanecer em sua existência por meio de composições com o que há em sua volta. Quando são feitos bons encontros, a potência se expande. Os maus encontros, por sua vez, diminuem a potência de agir. De qualquer forma, sempre há um poder de afetar e de ser afetado.

A partir dessa análise, não é possível pensar em processos de dominação de uma "massa compacta e homogênea", mas em uma "heterogeneidade plural, acentrada, como rede de mentes e corpos, de inteligências e de afetações, de sensibilidades e criatividade, de gestações e invenções". É a esse conjunto que se chama "multidão". Como explica Pelbart (2007), o poder contemporâneo não apresenta "positividade nenhuma", "ele é apenas um vampiro que vive da vitalidade da multidão, até que ela tome posse de sua própria potência".

Como essa discussão pode contribuir para as leituras sobre o circuito artístico atual?

\section{A potência da criação}

O conceito de arte que predominou principalmente durante o Romantismo, e que ainda hoje repercute, emergiu na Europa no final do século XVIII, quando os grandes mecenas foram, em boa parte, substituídos pela crítica acadêmica e pelo público anônimo que percorria museus e teatros em busca de novidades. O talento dos artistas e a originalidade das obras passavam a ser características mais valorizadas do que os motivos ou as dificuldades de ordem técnica. Por trás dessa dinâmica, havia o pensamento de que as artes são produtos do gênio, entendido por Kant (2012), entre outros filósofos da época, como um dom da natureza. Esse modo de olhar para as artes diluía os critérios tangíveis que determinavam o preço das obras, e o mercado passava a ser baseado na reputação dos autores e no desejo dos compradores, crescendo a partir de uma lógica financeira: a do investimento e do risco.

Ainda segundo Kant (ibidem), a aptidão da natureza para produzir coisas belas, que se revela também no gênio, promove um livre acordo entre as três faculdades humanas: a imaginação, o entendimento e a razão. Isso significa que, na contemplação de uma obra-prima, não se sente por ela nenhum desejo, mas um prazer "desinteressado", o que, para o filósofo, faria com que a arte fosse "comunicável universalmente", capaz de proporcionar um "acordo comum" entre as pessoas.

Essa maneira de pensar também tinha decorrências políticas. Schiller (2011, p. 37) acreditava que a divisão de tarefas nas fábricas e o consumo de bens padronizados 
separavam "a fruição do trabalho" e "o esforço da recompensa". O homem, fragmentado dessa maneira, não seria capaz de desenvolver a "harmonia do seu ser" e poderia se tornar uma "mera reprodução de sua ocupação, de sua ciência". O autor via na arte um modo de restaurar a integridade que havia se perdido, de forma que os ideais de "igualdade" e "liberdade" se tornassem possíveis.

Ocorre que a universalidade da arte e o papel do gênio foram revistos ao longo da história. Bourdieu (1986), por exemplo, investigou o conceito de capital cultural, afirmando que, ao contrário do que se pensava até então, o circuito artístico revela certa estrutura de interesses que contribui para a distinção entre as classes sociais. Isso acontece porque o "campo cultural", como denominado pelo autor, não é, de fato, um espaço autônomo, mas um ambiente permeado por relações de poder. Nele, o capital cultural, adquirido pelas instituições de ensino e pelo contexto familiar, converte-se em capital social e econômico.

Mas essa leitura, proposta nos anos 1980, também parece insuficiente. As artes já não são os principais meios de distinção simbólica, uma vez que os bens de consumo se tornaram estéticos e os gêneros midiáticos se apropriaram da imagem, do som, da literatura, ora reproduzindo obras já consagradas, ora criando suas próprias obras. O contrário também é verdadeiro: as artes muitas vezes usam a linguagem midiática em estéticas digitais, instalações, vídeos, entre outros.

Há, ainda, um ponto fundamental a ser ressaltado: se o trabalho já não se restringe ao tempo fragmentado das fábricas e dos escritórios, mas abrange todas as dimensões da vida, apropriando-se da cognição, da imaginação e dos afetos, as atividades culturais e, especificamente, as artísticas passam a ser percebidas como uma fonte de riquezas, retomando o que foi discutido no início deste artigo. É também por isso que a diversidade cultural vem sendo tão valorizada.

Para Bakhtin (2010), as linguagens se formam a partir de uma confluência de vozes muitas vezes contraditórias. Mas uma obra sempre exprime uma singularidade do autor que a criou e abre, dessa forma, a possibilidade do novo, que pode ser usado em outras combinações. São os valores intangíveis que emergem dessas redes, dessa cooperação na maioria das vezes anônima, que são cooptados pelo capitalismo. Na prática, os artistas passam a ser vistos como potenciais empreendedores, não somente por questões explicitamente financeiras, mas porque, como analisado por Foucault, eles investem todos os recursos de que dispõem, todo o seu capital humano, para gerar uma riqueza. É sobre essa riqueza que se debruçam políticos e teóricos da economia criativa ou da economia da cultura. Como canalizar os recursos em prol de um desenvolvimento econômico e social, deixando aflorar a multiplicidade que, afinal, é o que alimenta a criação, o que gera o novo?

As estratégias biopolíticas já foram amplamente discutidas: a promoção das culturas locais, a profissionalização do setor, a sustentabilidade econômica das artes e, principalmente, o apelo por criatividade. Mas como os artistas respondem a essa demanda? Canclini (2012, p. 235) sugere uma possibilidade. Partindo do "vazio que o esgotamento 
da(s) estética(s) moderna(s) deixou", ele busca "entender as mudanças na atuação dos artistas e demais participantes do campo", a "construção de redes" e "seus comportamentos variáveis". Embora o fazer artístico seja "poroso a muitas instâncias sociais", alguns projetos com intenção estética persistem. Além disso, há um "deslocamento" das práticas "baseadas em objetos" para as "práticas situadas em contextos até chegar à inserção das obras em meios, redes e interações sociais". Tendo em vista essa complexidade, o autor propõe uma "estética da iminência", que se refere:

[...] a esse estar no limiar entre o fora e o dentro, ser obra artística e ser mercadoria, exibir-se em museus e em uma organização de direitos humanos, enunciar-se como autor e duvidar de seu poder. (ibidem, p. 240)

Contudo, conclui Canclini (ibidem, p. 245, 246), a iminência não tem a ver com o "efêmero melancólico", mas com a "afirmação da vida", "como disposição ao que pode chegar, como atenção e espera", como um "modo de se abrir ao desconhecido". Neste sentido, a tarefa da arte não seria "organizar a diversidade", mas "valorizar o iminente onde o dissenso é possível". Os artistas ouvem as diversas vozes que se elevam na sociedade e seguem "imaginando os desacordos". Um exemplo é o espetáculo Farinha com açúcar ou sobre a sustança de meninos e homens ${ }^{2}$, do Coletivo Negro, com texto e dramaturgia de Jé Oliveira. A peça narra a vida de um homem que nasceu e cresceu na favela. Seus primeiros elementos são a violência e a morte:

Apesar de ficção, obra, criação, não teremos ilusão nessa peça. Esse tipo de coisa acontece na vida de alguns. As pessoas morrem de muitos modos, mas alguns modos são moldes das mortes de alguns só. (OLIVEIRA, s.d.)

Aos poucos, aparecem também os encontros amorosos, as relações familiares, as amizades. Na obra poética, que transita pelo teatro e pela música, as questões sociais adquirem uma forma estética, erguendo um manifesto pela vida:

Esse é o nosso manifesto pela existência: a potência do possível das vidas, o respiro mesmo sob os escombros, o efêmero de nós que fica (...). A nossa existência é maciça, é vida que brota dos poros, é solo que vira dueto, é duelo com a morte, é roda de escuta que enxuga todo o sangue derramado por corações rijos. (ibidem)

O espetáculo ilustra a criação do novo a partir de relatos diversos, ultrapassando questões sociais para transformá-las em obra. É no embate com as tentativas de apropriação dessa riqueza para fins socioeconômicos que boa parte das manifestações artísticas se situa atualmente.

2 A peça esteve em cartaz de 7 a 17 de abril de 2016 no Complexo Cultural Funarte SP. 


\section{Considerações finais}

Como este artigo procurou mostrar, as atividades criativas, entre elas as artes, têm sido cada vez mais iluminadas, em sua multiplicidade, como recursos abundantes e intangíveis. Isso leva a denúncias da exploração dos trabalhadores no campo cultural e a críticas à busca da "criatividade pela criatividade", o que poderia "esvaziar" o sentido dessa palavra. Porém, quando o capitalismo enuncia uma riqueza que emerge dos bens comuns, ao mesmo tempo em que procura se apropriar de todos os domínios da vida, a própria vida se abre como um campo de resistência (PELBART, 2007). A mesma coisa pode acontecer com a criação artística.

Ao desvelar acordos e desacordos, confluências e divergências de vozes, a arte se apresenta como um campo de disputa política, o que se torna evidente não somente quando os artistas participam da formulação de novas leis ou editais, mas principalmente quando transformam relatos diversos em novas estéticas. É o caso dos movimentos de arte negra, das músicas de matrizes africanas, da cultura hip-hop que é incorporada à dança contemporânea, das pinturas que se mostram nas ruas e dos grafites que são expostos em museus. É claro que nem todas as propostas de fato renovam ou exploram as linguagens, algumas repetem padrões ou adaptam-se aos modelos estabelecidos por circuitos comerciais, curadorias ou comissões de seleção. Mas o que está em jogo para as políticas públicas e as iniciativas privadas é justamente a promoção da diversidade e a sustentabilidade das ações artísticas e culturais, ou seja, a capacidade de empreender. Para que esse movimento também gere o novo, é preciso encontrar brechas na burocracia e nos processos econômicos, abrindo espaço para que as redes de criação realmente se expandam, ampliando a potência humana de imaginar.

Sharine Machado Cabral Melo é doutora em Comunicação e Semiótica pela PUC-SP, com período de bolsa sanduíche, financiada pela CAPES, na University of Leeds - Reino Unido. É administradora cultural na Fundação Nacional de Artes - Funarte SP.

sharinemelo@gmail.com.

\section{Referências}

AGAMBEN, G. O homem sem conteúdo. Belo Horizonte: Autêntica, 2012.

BAKHTIN, M. Questões de literatura e de estética: a teoria do romance. São Paulo: Hucitec, 2010.

BOURDIEU, P. The forms of capital. In: J. E. RICHARDSON, Handbook of theory of research for the sociology of education. Nova York: Greenword Press, 1986.

BRASIL. Ministério da Cultura. (s.d.). Política Nacional das Artes. Disponível em http://culturadigital. 
br/pna/artes-visuais/capitulo-i-do-estado/. Acesso em 01 Fev. 2016.

Metas do Plano Nacional de Cultura. Brasília: Ministério da Cultura, 2011

O que movimenta a cultura. Disponível em: https://www.facebook.com/MinisterioDaCultura. Acesso em 28 Jun. 2016.

CANCLINI, N. G. A sociedade sem relato: antropologia e estética da iminência. São Paulo: Edusp, 2012 COSTA, R. da. Inteligência coletiva: comunicação, capitalismo cognitivo e micropolítica. In: Revista Famecos. Porto Alegre, p. 61-68, dez 2008.

DELEUZE, G. Foucault. São Paulo: Brasiliense, 2005.

FLORIDA, R. The rise of the creative class, revisited. Nova York: Basic Books, 2012

FOUCAULT, M. As palavras e as coisas. São Paulo: Martins Fontes, 2007.

Nascimento da biopolítica: curso dado no Collège de France (1978-1979). São Paulo: Martins Fontes, 2008.

Resumo dos cursos do Collège de France (1970-1982). Rio de Janeiro: Zahar, 2013.

GIELEN, P. Criatividade e outros fundamentalismos. São Paulo: Annablume, 2015

GREINER, C. Por uma economia das generosidades. Dança, Salvador, v. 1, n. 1, p. 9-18, jul-dez 2012. . A arte de territorializar e criar vida. In: GREINER, C. et al. (org.) Cartografias Rumo Itaú Cultural Dança 2012-2014. São Paulo: Itaú Cultural, 2014.

HESMONDHALGH, D. The Cultural Industries. Londres: Sage, 2013.

KANT, I. Crítica da faculdade do juízo. Rio de Janeiro: Forense Universitária, 2012.

MOULIER-BOUTANG, Y. Cognitive capitalism. Cambrigde: Polity, 2011.

NEGRI, A.; LAZZARATO, M. Trabalho imaterial: formas de vida e produção de subjetividade. Rio de Janeiro: DP\&A, 2001.

OAKLEY, K. The disappearing arts: creativity and innovation after the creative industries. In: International Journal of Cultural Policy. Londres: Routledge, v. 15, n. 4, 403-13, nov 2009.

OLIVEIRA, J. Farinha com açúcar ou sobre a sustança de meninos e homens. No prelo.

PELBART, P. Mutações contemporâneas. In: Revista Cinética. Ensaios Críticos. Disponível em http:// www.revistacinetica.com.br/cep/peter_pal.htm. Acesso em 01 Fev. 2016.

Foucault versus Agamben? In: Revista Ecopolítica. São Paulo, n. 5, pp. 50-64, jan-abr 2013.

SCHILLER, F. A educação estética do homem. São Paulo: Iluminuras, 2011.

SEBRAE. A atuação do SEBRAE na economia criativa. Disponível em: http://www.sebrae.com.br/sites/ PortalSebrae/artigos/a-atuacao-do-sebrae-na-economia-criativa. Acesso em: 28 Jun. 2016.

SPINOZA, B. Ética. Belo Horizonte: Autêntica, 2009.

THROSBY, D. The concentric circles model of the cultural industries. In: Cultural Trends. Oxon: Taylor \& Francis, v. 17, n. 3, p. 147-64, 2008.

VEYNE, P. Foucault: seu pensamento, sua pessoa. Rio de Janeiro: Civilização Brasileira, 2011. 